\title{
Enhanced high temperature ethanol production using newly isolated thermotolerant yeast Pichia kudriavzevii NUPHS from Thailand
}

\author{
Pongsanat Pongcharoen $^{\mathrm{a}, \mathrm{b}, *}$, Wittaya Tawong ${ }^{\mathrm{a}, \mathrm{b}}$, Siriwat Kucharoenpsaibul ${ }^{\mathrm{c}}$ \\ a Department of Agricultural Science, Faculty of Agriculture, Natural Resources and Environment, \\ Naresuan University, Phitsanulok 65000 Thailand \\ b Center of Excellence in Research for Agricultural Biotechnology, Naresuan University, Phitsanulok \\ 65000 Thailand \\ c Department of Microbiology and Parasitology, Faculty of Medical Science, Naresuan University, \\ Phitsanulok 65000 Thailand
}

*Corresponding author, e-mail: pongsanatp@nu.ac.th

Received 10 Sep 2020

Accepted 5 Dec 2020

\begin{abstract}
New industrial microorganisms are required to improve biofuel production with a key factor being ethanol fermentation at a high temperature. In this study, 222 yeast isolates from sugarcane field soil from lower Northern Thailand were isolated using yeast extract peptone dextrose medium supplemented with $4 \%(\mathrm{v} / \mathrm{v})$ ethanol. The isolates were characterized for growth performance under stress conditions and for fermentation activity at high temperatures. A phylogenetic analysis of 25 thermotolerant yeasts grouped the isolates into clusters of Candida blankii, Saccharomyces cerevisiae and Pichia kudriavzevii. Two isolates, P. kudriavzevii NUPHS33 and NUPHS34, exhibited high temperature and ethanol tolerance levels of up to $45^{\circ} \mathrm{C}$ and $15(\mathrm{v} / \mathrm{v})$, respectively. Ethanol production upon utilization of glucose as a carbon source was determined by gas chromatography. The highest ethanol concentration of $P$. kudriavzevii NUPHS33 and NUPHS34 reached $61.51 \pm 1.01 \mathrm{~g} / 1$ at $45^{\circ} \mathrm{C}$ and $69.79 \pm 1.54 \mathrm{~g} / 1$ at $40^{\circ} \mathrm{C}$, respectively, which is significantly greater than the amount of ethanol produced by the industrial strain $S$. cerevisiae TISTR5606 $(p<0.01)$. Therefore, the newly isolated thermo- and ethanol-tolerant $P$. kudriavzevii NUPHS33 and NUPHS34 are highly competent yeasts for high-temperature ethanol fermentation. Our results might be useful to further improve commercial-scale bioethanol production.
\end{abstract}

KEYWORDS: bioethanol fermentation, thermo- and ethanol-tolerant yeast, Pichia kudriavzevii, sugarcane soil, lower Northern Thailand

\section{INTRODUCTION}

The overconsumption of fuel and petroleumderived products is a significant threat to human society and resource management. Biofuel, especially bioethanol production, has received widespread attention as a potentially renewable energy source [1]. Yeasts have proven to be more effective than bacteria due to their ability to tolerate various stresses during the fermentation process [24]. However, there have been a limited number of attempts to obtain yeasts from laboratory isolates that are capable of growth and fermentation at or above $40^{\circ} \mathrm{C}$ [2].

The rich diversity of yeast in tropical regions has been extensively studied, especially in Thailand, due to its diverse ecosystems in both natural and humanrelated environments. It has been reported that industrial yeast strains were preferentially isolated from natural habitats, particularly from soil and plant substrates [5-8]. Soil is a true ecological habitat of microorganisms because it is rich in nutrients from natural processes in ecosystems [9]. In Thailand, sugarcane fields are a major agricultural land use and are favored areas as one of the best niches for various yeast species [7]. Screening of yeasts from specific ecological niches such as soil in hot regions, agricultural fields, juice as well as clay soil appears to be the main sources of yeasts isolated for industrial production. It has been demonstrated that natural strains have many distinctive characteristics and specific properties which are not possessed by industrial strains [10-12]. Therefore, there is great interest in discovering distinct yeasts with the ability to produce higher ethanol concentrations during the process of fermentation at high temper- 
ature.

Thermotolerant yeasts have significant advantages in the biotechnology industry by reducing cooling costs, reducing the risk of contamination and increasing fermentation rates, making the process more economical. These advantages are particularly important for industrial ethanol fermentation in tropical countries such as Thailand, where average daytime temperatures are usually high throughout the year [2]. To overcome the current limitations and challenges of industrial fermentation, new thermotolerant and ethanol-producing yeasts that are capable of growth and ethanol production under a variety of inhibitory conditions are required. Many studies have isolated various naturally thermotolerant yeasts such as Saccharomyces cerevisiae, Pichia kudriavzevii and Kluyveromyces marxianus for use in ethanol production under optimized conditions $[2,6,13]$. However, while these species exhibit good ethanol production, there are still certain challenges including a lower yield of ethanol at higher temperatures and a lower tolerance to high ethanol concentrations. Hence, the introduction of new thermotolerant yeasts isolated from natural environments is essential to develop higher fermentation efficiency.

Thus, the purpose of this research was to isolate and characterize thermotolerant yeasts from soil samples collected from sugarcane fields situated in lower Northern Thailand for ethanol production at high temperature. Their physiology under heat and ethanol stresses was evaluated. Among them, 2 thermotolerant yeasts identified as $P$. kudriavzevii, NUPHS33 and NUPHS34, presented distinctive characteristics with high tolerance to ethanol and heat stresses. Finally, the ethanol production of the isolated yeasts under high temperature fermentation was also investigated.

\section{MATERIALS AND METHODS}

\section{Yeast sampling and screening of thermotolerant yeast}

Soil samples were collected from sugarcane fields situated in lower Northern Thailand including Tak (TK), Sukhothai (ST), Uttaradit (UD), Phitsanulok (PHS), Kamphaeng Phet (KP), Phichit (PC), Pethchabun (PCB) and Nakhon Sawan (NS) provinces. Three sampling sites were selected from each location (Fig. 1, Table S1). The time period of sample collection was from September 2017 to May 2018. The top $10 \mathrm{~cm}$ of soil located beneath the sugarcane plants at each sampling site were collected in tripli- cate according to the method of Koutinas et al [6]. Two grams of soil sample were aseptically placed in $50 \mathrm{ml}$ of enrichment media consisting of $1 \%$ yeast extract, $2 \%$ peptone and $2 \%$ glucose (YPD), supplemented with $0.025 \%$ sodium propionate (P1880; Sigma; Oakville, Canada), 0.02\% chloramphenicol (C0378; Sigma; St. Louis, USA) and 4\% (v/v) ethanol, and samples were incubated at $30^{\circ} \mathrm{C}$ for $24 \mathrm{~h}$ [14]. The next day a loopful of the enriched culture was streaked onto YPD agar plates containing the same medium, and plates were then incubated at $45^{\circ} \mathrm{C}$ until yeast colonies appeared [8]. For a reference strain, S. cerevisiae TISTR5606, an industrial ethanol-producing strain, was purchased from the Thailand Institute of Scientific and Technological Research, Bangkok, Thailand.

\section{Screening of thermotolerant and ethanol-tolerant yeasts}

The thermotolerant yeast strains were further selected for ethanol tolerance based on their growth performance under increasing ethanol concentrations $(7-15 \% \mathrm{v} / \mathrm{v})$ using the modified method described by Techaparin et al [10] and Pongcharoen and Kawano-Kawada [15]. Each of the isolated yeast strains was streaked onto YPD agar plates containing 7, 10, 13 and 15\% (v/v) ethanol (added aseptically), and plates were incubated at $30^{\circ} \mathrm{C}$. The growth of yeast was monitored, and each experiment was repeated twice.

\section{Fermentation activity test by selected thermotolerant yeasts}

Screening of yeast strains for ethanol production was undertaken using a Durham fermentation tube in YP broth containing $2 \%(\mathrm{w} / \mathrm{v})$ glucose as the carbon source. Briefly, $0.1 \mathrm{ml}$ of an overnight culture of cells was inoculated into $9 \mathrm{ml}$ YPD broth in a $18 \times 150 \mathrm{~mm}$-test tube containing a Durham tube, and tubes were incubated at $45^{\circ} \mathrm{C}$ for $24-72 \mathrm{~h}$ [7]. Yeast isolates capable of producing $\mathrm{CO}_{2}$ gas were selected for further screening and identification.

The fermentation activity of the yeast isolates was determined using various carbon sources by the modified method of Phoung et al [16]. YP broth containing $2 \%(\mathrm{w} / \mathrm{v})$ fructose, sucrose or xylose was investigated, and $\mathrm{CO}_{2}$ production was observed. All experiments were run in triplicate.

Ethanol productivity of thermotolerant yeasts at high temperature

Thermotolerant yeast isolates aerobically precultivated to exponential phase in YPD broth at 

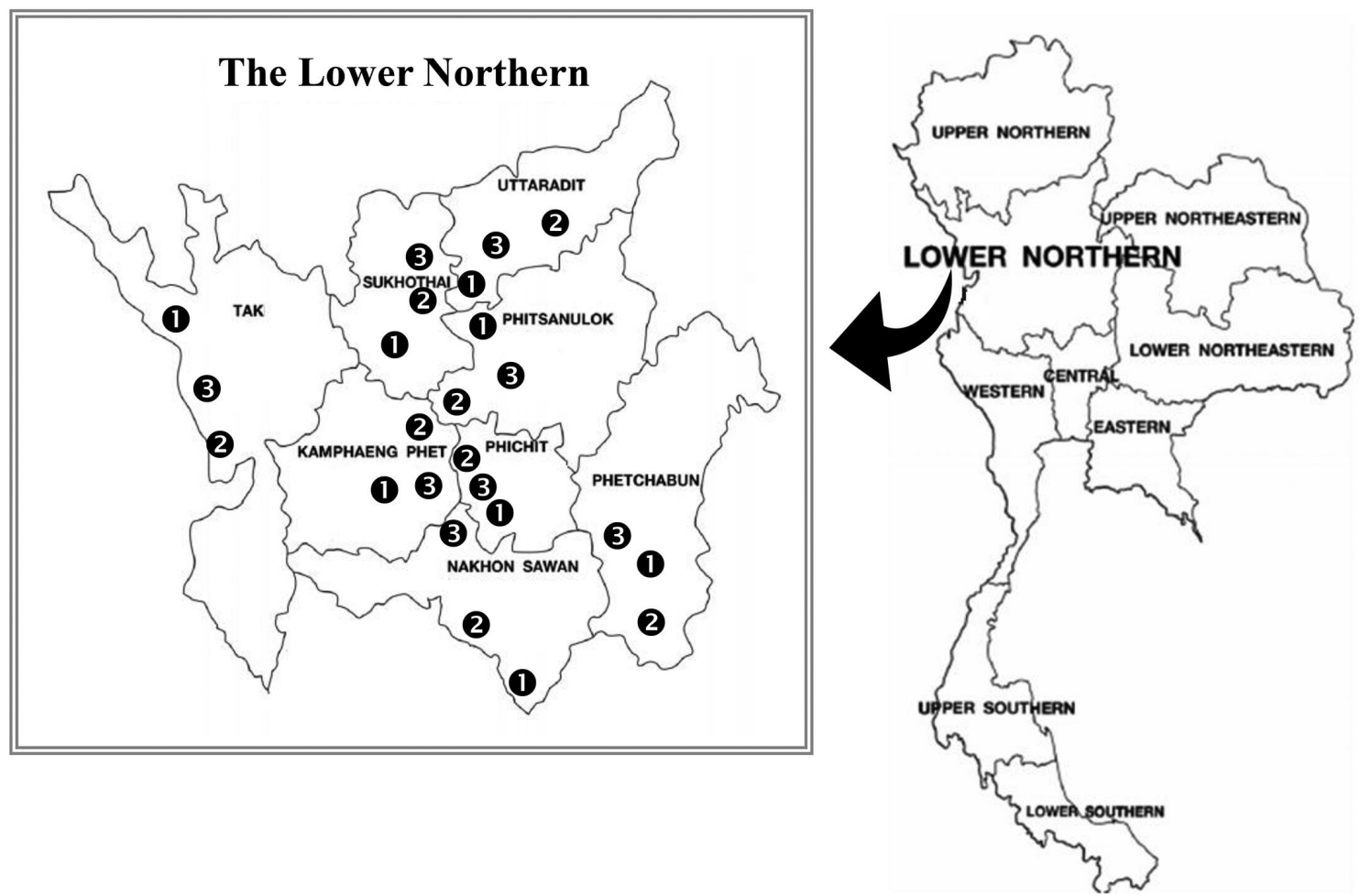

Fig. 1 Sample collection sites of the sugarcane fields in lower Northern Thailand. Soil samples were randomly collected from different locations including 8 provinces: Tak (TK), Sukhothai (ST), Uttaradit (UD), Phitsanulok (PHS), Kamphaeng Phet (KP), Phichit (PC), Phetchabun (PCB) and Nakhon Sawan (NS).

$30^{\circ} \mathrm{C}$ were inoculated into $250 \mathrm{ml}$ Erlenmeyer flasks containing $100 \mathrm{ml}$ YPD broth with $160 \mathrm{~g} / \mathrm{l}$ glucose as the carbon source. The initial $\mathrm{OD}_{660}$ value of cells before further cultivation was 0.1, and cells were incubated at specific temperatures in a shaker incubator (150 rpm) [17]. In order to measure the concentrations of ethanol by gas chromatography (GC-14B apparatus, Shimadzu, Kyoto, Japan), the fermentation broth was collected after $48 \mathrm{~h}$ of incubation, and supernatants were collected by centrifugation at $16200 \times \mathrm{g}$ for $10 \mathrm{~min}$ at $4{ }^{\circ} \mathrm{C}$ for further analysis. The statistical analysis of the results was conducted by a variance analysis (One-way ANOVA) at a 99\% confidence level using the $\mathrm{R}$ program (version 3.2.4). Duncan's multiple range test was employed to determine the difference of average values when the results from ANOVA were significant $(p<0.01)$.

\section{Molecular characterization of thermotolerant yeast strains}

Genomic DNA of all isolates used in this study was extracted by the lithium acetate (LiOAC)
DNA extraction method [18]. The D1/D2 domain from the large subunit (LSU; 26S) rDNA region was amplified using primers NL-1 ( $5^{\prime}$-GCATATCAATAAGCGGAGGAAAAG- ${ }^{\prime}$ ) and NL-4 (5'-GGTCCGTGTTTCAAGACGG-3'). The temperature cycling conditions for the amplification were performed following the description of Kurtzman and Robnett [19]. The PCR products were purified and used as templates for sequencing reactions with $A B I$ BigDye Terminator version 3.1 Cycle sequencing kit and then analyzed on an automated Prism 3730XL DNA Analyzer (Applied Biosystems, California, USA). The D1/D2 LSU rDNA sequences obtained in this study and the reference sequences of other thermotolerant yeasts retrieved from the GenBank were aligned using the CLUSTAL W Multiple Sequence Alignment Program [20]. The maximum likelihood (ML) tree was computed with PhyML 3.0 [21] using the GTR+G+I model. The neighbor joining ( $\mathrm{NJ}$ ) tree was generated using the p distance method provided by MEGA7 [22]. Statistical significance was undertaken with a bootstrap test for 100 replicates in the case of the 
Table 1 Number of isolated yeasts from different locations at temperature of $45^{\circ} \mathrm{C}$ and ethanol concentration $(7,10$, 13 and 15\% v/v) on YPD agar.

\begin{tabular}{lcrrrr}
\hline Sample & $\begin{array}{c}\text { Number of isolates } \\
\text { grow up to } 45^{\circ} \mathrm{C}\end{array}$ & \multicolumn{4}{c}{$\begin{array}{c}\text { Number of isolates tolerant to } \\
\text { ethanol concentration (v/v) }\end{array}$} \\
\cline { 3 - 6 } & & $7 \%$ & $10 \%$ & $13 \%$ & $15 \%$ \\
\hline UD3 & 13 & 13 & 13 & 13 & 12 \\
PHS1 & 52 & 52 & 52 & 52 & 37 \\
PC1 & 40 & 40 & 40 & 40 & 14 \\
PC2 & 50 & 50 & 50 & 50 & 0 \\
PCB3 & 33 & 33 & 33 & 33 & 33 \\
NS1 & 8 & 8 & 0 & 0 & 0 \\
NS2 & 26 & 26 & 0 & 0 & 0 \\
\hline Total & 222 & 222 & 188 & 188 & 96 \\
\hline
\end{tabular}

ML tree and with 1000 replicates for the NJ tree. The D1/D2 LSU rDNA sequences of all isolates used in this study were deposited in GeneBank (accession numbers LC508273-LC508297).

\section{RESULTS}

\section{Isolation of thermotolerant yeast from soil from} lower Northern Thailand

Twenty-four soil samples from sites in lower Northern Thailand (Fig. 1, Table S1) were collected and screened for thermotolerant yeasts. A total of 222 isolates capable of growing at temperatures of up to $45^{\circ} \mathrm{C}$ were obtained (Fig. 2, which comprised 13 isolates from Uttaradit (UD3 isolates), 52 isolates from Phitsanulok (PHS1 isolates), 90 isolates from Phichit (PC1 and PC2 isolates), 33 isolates from Phetchabun (PCB3 isolates) and 34 isolates from Nakhon Sawan (NS1 and NS2 isolates) (Table 1). Notably, no thermotolerant yeast isolates were obtained from soil samples taken from Tak, Sukhothai or Kamphaeng Phet. According to the definition established by Chamnipa et al [5] and Sree et al [12], all 222 isolates were categorized as thermotolerant yeasts since they were able to grow at temperatures higher than $40^{\circ} \mathrm{C}$.

\section{Ethanol tolerance capability test of thermotolerant yeast}

The 222 thermotolerant yeast isolates were further evaluated for their ethanol-tolerance capabilities in synthetic YPD agar supplemented with varied ethanol concentrations (7-15\% v/v). All 222 yeast isolates and the reference strain $S$. cerevisiae TISTR5606 could grow on YPD agar containing up to $7 \%(\mathrm{v} / \mathrm{v})$ ethanol. Growth of UD3, PHS1, PC1, PC2 and PCB3 isolates was clearly observed at $10 \%(\mathrm{v} / \mathrm{v})$ ethanol concentration, whereas growth of the NS1 and NS2 isolates could not be determined. Among the 222 isolates, 188 isolates exhibited the ability to grow on YPD agar containing up to $13 \%(\mathrm{v} / \mathrm{v})$ ethanol, but no growth was observed in the reference strain. Notably, 96 isolates were observed to grow in agar containing 15\% (v/v) ethanol (Table 1). The growth pattern of UD3 isolates under different ethanol concentrations was shown in Fig. 3. Growth performance of PHS1, PC1, PC2, PCB3, NS1 and NS2 isolates on YPD agar plates containing ethanol was demonstrated in supplementary data (Fig. S2a-f).

\section{Screening of thermotolerant yeast for ethanol production and sugar utilization}

The primary screening was undertaken by fermentation in YPD broth using a Durham fermentation tube. All 188 yeast isolates which could tolerate an ethanol concentration of 13\% ( $\mathrm{v} / \mathrm{v})$ were subjected to a sugar fermentation testing using $2 \%(\mathrm{w} / \mathrm{v})$ glucose as the carbon source in Durham tubes at $45^{\circ} \mathrm{C}$. The results showed that only 25 isolates of yeast including NUPCB3-3, NUPCB3-4, NUPCB3-8, NUPCB3-9, NUPCB3-10, NUPCB3-14, NUPCB3-15, NUPCB3-19, NUPCB3-20, NUPCB3-25, NUPCB3-26, NUPCB3-27, NUPCB3-28, NUPCB3-29, NUPCB3-30, NUPCB3-31, NUPCB3-32, NUPCB3-33, NUUD3-2, NUUD3-4, NUUD3-8, NUUD3-9, NUUD3-11, NUPHS33 and NUPHS34 showed fermentative activity and produced $\mathrm{CO}_{2}$ gas at $45^{\circ} \mathrm{C}$, while others exhibited no gas production. Furthermore, the 25 yeast isolates were also tested for fermentation at $30^{\circ} \mathrm{C}$ using other hexose (sucrose and fructose) and pentose (xylose) sugars to determine their ability to utilize different carbon sources. The results showed that all NUPCB could utilize both hexose and pentose sugars; however, NUUD and NUPHS were unable to utilize fructose, sucrose or xylose. The reference strain was able to generate fermentation using sucrose (Table S2).

\section{Ethanol productivity of thermotolerant yeast at high temperature}

The effect of a high temperature $\left(45^{\circ} \mathrm{C}\right)$ on ethanol fermentation in YPD medium containing $16 \%$ (w/v) glucose for all 25 yeast isolates was investigated by gas chromatography. The ethanol concentration of 23 yeast isolates namely NUPCB3-3, NUPCB3-4, NUPCB3-8, NUPCB3-9, NUPCB3-10, NUPCB3-14, NUPCB3-15, NUPCB3-19, NUPCB3-20, NUPCB3-25, NUPCB3-26, NUPCB3-27, NUPCB3-28, NUPCB3-29, NUPCB3-30, NUPCB3-31, 

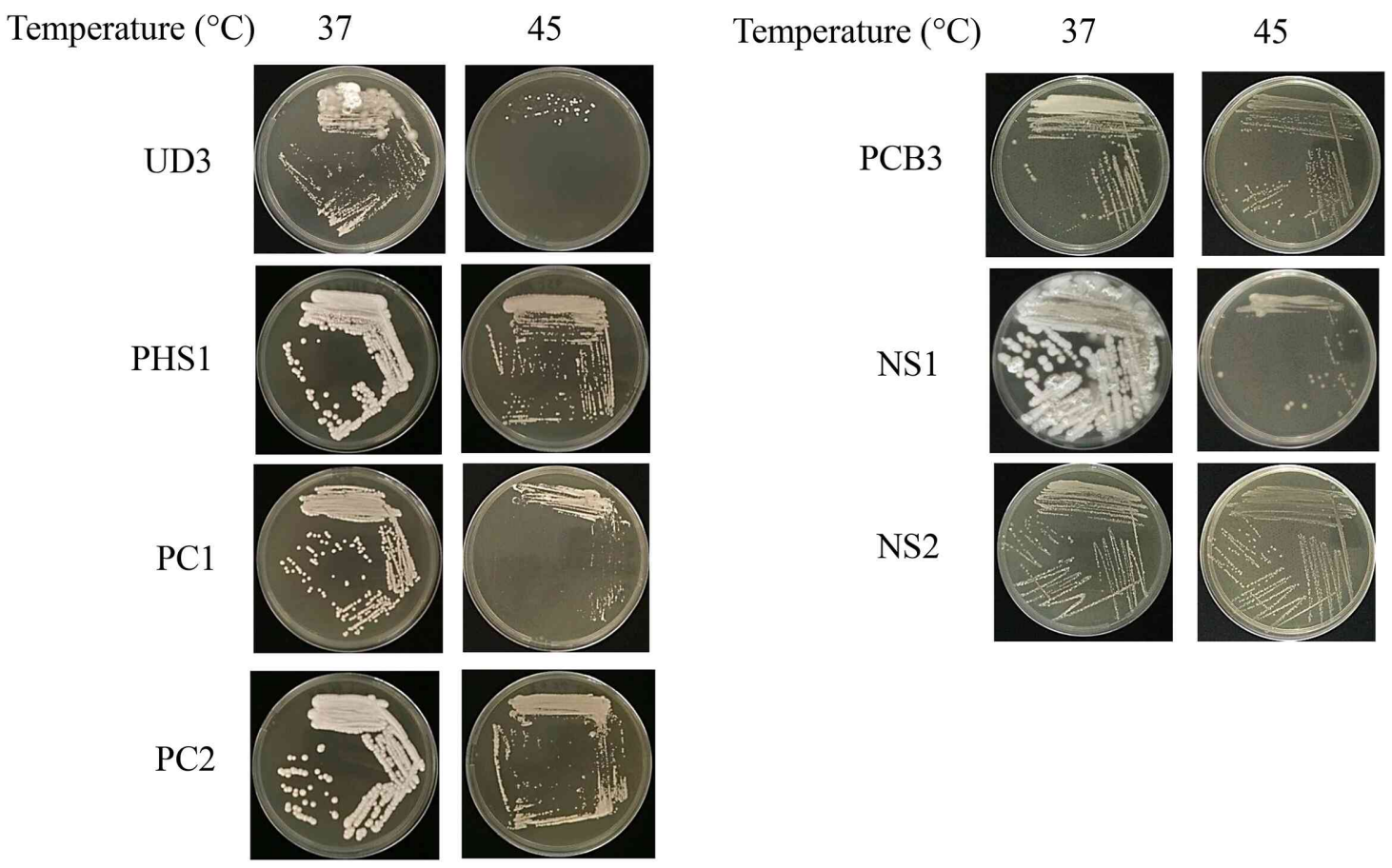

Fig. 2 Growth performance of isolated yeasts on YPD agar supplemented with 4\% (v/v) ethanol and incubated at 37 and $45^{\circ} \mathrm{C}$. Abbreviations: Uttaradit, UD; Phitsanulok, PHS; Phichit, PC; Phetchabun, PCB and Nakhon Sawan, NS. Numbers indicated as 1, 2 and 3 represent sampling sites from different locations.

Table 2 Ethanol production efficiency of isolates, NUPHS33 and NUPHS34, at temperatures of 37,40 and $45^{\circ} \mathrm{C}$ for $48 \mathrm{~h}$ incubation time compared to that of the reference isolate S. cerevisiae TISTR5606. Data are expressed as mean \pm standard deviation.

\begin{tabular}{|c|c|c|c|c|c|c|c|c|c|}
\hline \multirow{3}{*}{ Isolate } & \multicolumn{9}{|c|}{ Temperature $\left({ }^{\circ} \mathrm{C}\right)$} \\
\hline & \multicolumn{3}{|c|}{37} & \multicolumn{3}{|c|}{40} & \multicolumn{3}{|c|}{45} \\
\hline & $P(g / l)$ & $\mathrm{QP}(\mathrm{g} / \mathrm{l} / \mathrm{h})$ & YP/S (g/g) & $P(g / l)$ & QP $(\mathrm{g} / \mathrm{l} / \mathrm{h})$ & $\mathrm{YP} / \mathrm{S}(\mathrm{g} / \mathrm{g})$ & $P(g / l)$ & $\mathrm{QP}(\mathrm{g} / \mathrm{l} / \mathrm{h})$ & $\mathrm{YP} / \mathrm{S}(\mathrm{g} / \mathrm{g})$ \\
\hline $\begin{array}{l}\text { NUPHS33 } \\
\text { NUPHS34 }\end{array}$ & $\begin{array}{l}65.38 \pm 0.21 \\
64.92 \pm 1.33\end{array}$ & $1.36 \pm 0.00$ & $0.41 \pm 0.00$ & $54.82 \pm 1.29^{\circ}$ & $1.14 \pm 0.03^{c}$ & $0.34 \pm 0.01^{\mathrm{c}}$ & $61.51 \pm 1.01^{\mathrm{a}}$ & $1.28 \pm 0.02^{\mathrm{a}}$ & $0.38 \pm 0.01^{a}$ \\
\hline $\begin{array}{l}\text { NUPHS34 } \\
\text { TISTR5606 }\end{array}$ & $\begin{array}{l}64.92 \pm 1.33 \\
67.37 \pm 0.47\end{array}$ & $\begin{array}{l}1.35 \pm 0.03 \\
1.40 \pm 0.01\end{array}$ & $\begin{array}{l}0.41 \pm 0.01 \\
0.42 \pm 0.00\end{array}$ & $\begin{array}{l}69.79 \pm 1.54^{\circ} \\
60.96 \pm 0.48^{b}\end{array}$ & $\begin{array}{l}1.45 \pm 0.03^{\circ} \\
1.27 \pm 0.01^{b}\end{array}$ & $\begin{array}{l}0.44 \pm 0.01^{\mathrm{a}} \\
0.38 \pm 0.00^{\mathrm{b}}\end{array}$ & $\begin{array}{r}58.95 \pm 0.98^{\mathrm{a}} \mathrm{b} \\
2.12 \pm 0.05^{\mathrm{b}}\end{array}$ & $\begin{array}{l}1.23 \pm 0.02^{\mathrm{a}} \\
0.04 \pm 0.00^{\mathrm{b}}\end{array}$ & $\begin{array}{l}0.37 \pm 0.01^{\mathrm{a}} \\
0.01 \pm 0.00^{\mathrm{b}}\end{array}$ \\
\hline
\end{tabular}

Abbreviations: P, ethanol concentration $(\mathrm{g} / \mathrm{l})$; QP, ethanol productivity $(\mathrm{g} / \mathrm{l} / \mathrm{h})$; YP/S, ethanol yield $(\mathrm{g} / \mathrm{g})$. Values in the same condition of temperature with different superscripts ( $a, b$ and $c$ ) indicate variable with significant differences among yeast strains tested in the present study (ANOVA, $p<0.01$ ).

NUPCB3-32, NUPCB3-33, NUUD3-2, NUUD3-4, NUUD3-8, NUUD3-9 and NUUD3-11 showed low levels of ethanol as did the reference TISTR5606 strain (Table S3). Notably, 2 thermotolerant yeasts, NUPHS33 and NUPHS34, exhibited a high performance for ethanol production at 37, 40 and $45^{\circ} \mathrm{C}$. However, ethanol production of NUPHS33 $(65.38 \pm 0.21 \mathrm{~g} / 1)$ and NUPHS34 (64.92 $\pm 1.33 \mathrm{~g} / \mathrm{l})$ after fermentation at $37^{\circ} \mathrm{C}$ for $48 \mathrm{~h}$ of incubation was not different to that of strain TISTR5606 $(67.37 \pm 0.47 \mathrm{~g} / 1)$. At a fermentation temperature of $40^{\circ} \mathrm{C}$, the maximum ethanol concentration produced by NUPHS34 $(69.79 \pm 1.54 \mathrm{~g} / \mathrm{l})$ was significantly higher than that of reference strain $(60.96 \pm 0.48 \mathrm{~g} / 1 ; p<0.01)$. At the highest fermentation temperature of $45^{\circ} \mathrm{C}$, the isolates of NUPHS33 and NUPHS34 still produced high ethanol concentrations (NUPHS33 $(61.51 \pm 1.01 \mathrm{~g} / \mathrm{l})$ and NUPHS34 $(58.95 \pm 0.98 \mathrm{~g} / \mathrm{l}))$ as compared to the reference strain, which produced an ethanol concentration of $2.12 \pm 0.05 \mathrm{~g} / 1 \quad(p<0.01)$ (Table 2). 
Control; YPD
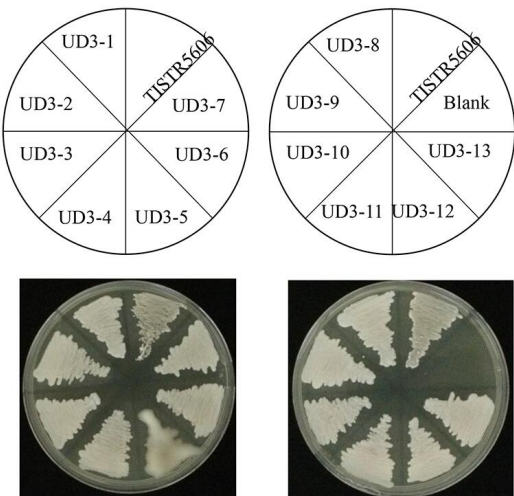

EtOH $7 \%(v / v)$
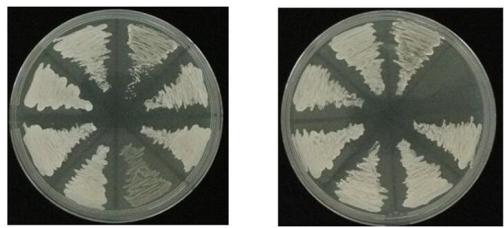

EtOH 13\%(v/v)
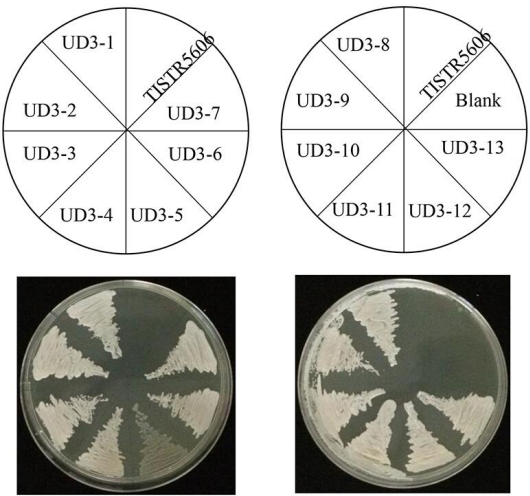

$\mathrm{EtOH} 15 \%(\mathrm{v} / \mathrm{v})$
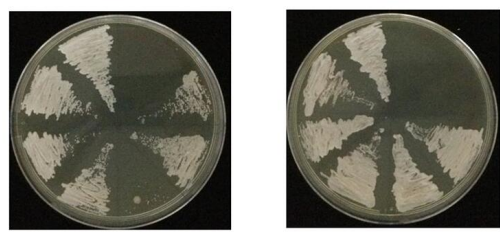

$\mathrm{EtOH} 10 \%(\mathrm{v} / \mathrm{v})$
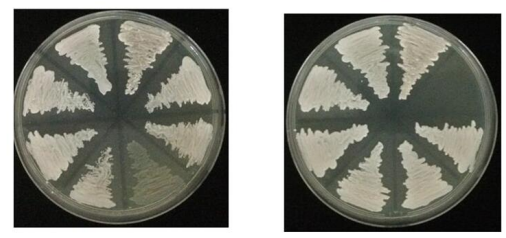

Fig. 3 Effect of ethanol stress on the cell growth of isolates UD3-1 to UD3-13 and S. cerevisiae TISTR5606 on YPD agar plates after incubation at temperature of $30^{\circ} \mathrm{C}$.

\section{Molecular identification of newly isolated thermotolerant yeasts}

The phylogenetic relationships of the 25 thermotolerant, ethanol producing yeasts were determined by comparing sequences of the D1/D2 regions available in the GeneBank sequence database to those of the newly isolated thermotolerant yeasts (Fig. 4). The isolates NUPCB3-3, NUPCB3-4, NUPCB3-8, NUPCB3-10, NUPCB3-14, NUPCB3-15, NUPCB3-19, NUPCB3-20, NUPCB3-25, NUPCB3-26, NUPCB3-27, NUPCB3-28, NUPCB3-29, NUPCB3-30, NUPCB3-31, NUPCB3-32 and NUPCB3-33 were identified as $S$. cerevisiae. The isolates NUPCB3-9, NUUD3-2, NUUD3-4, NUUD3-8, NUUD3-9 and NUUD3-11 were identified as Candida blankii. The isolates NUPHS33 and NUPHS34 were identified as P. kudriavzevii.

\section{DISCUSSION}

Thermotolerance is a preferred trait for yeast in biotechnological applications such as industrial fermentation or production of chemical industrial en- zymes and pharmaceuticals [23]. High temperature environments can act as a natural selection pressure, selecting thermotolerant strains. An ethanol concentration above $10 \%(\mathrm{v} / \mathrm{v})$ has been reported as a critical factor for yeast during the fermentation process, as a consequence of inhibition of cell division, reducing cell viability and increasing cell death [24]. The results obtained in this study indicate that the newly selected yeast isolates were thermotolerant and ethanol-tolerant yeasts. Colonies of $P$ kudriavzevii isolates NUPHS33 and NUPHS34 growing on YPD agar at $30^{\circ} \mathrm{C}$ were present as creamy-colored, butyrous and low convex with flattened centers. The cell shape became ovoid to elongated and usually existed singly when grown in YPD liquid medium at $30^{\circ} \mathrm{C}$. Differences in ethanol tolerance and other stresses might be due to differences in the natural sources for the isolation and strains of thermotolerant yeasts from those reported by Kaewkrajay et al [8], Techaparin et al [10] and Joshi and Patel [25]. For example, Limtong and colleagues [14] were successful in isolating K. marxianus DMKU 3-1042 from soil and water samples of sugarcane plantations by 


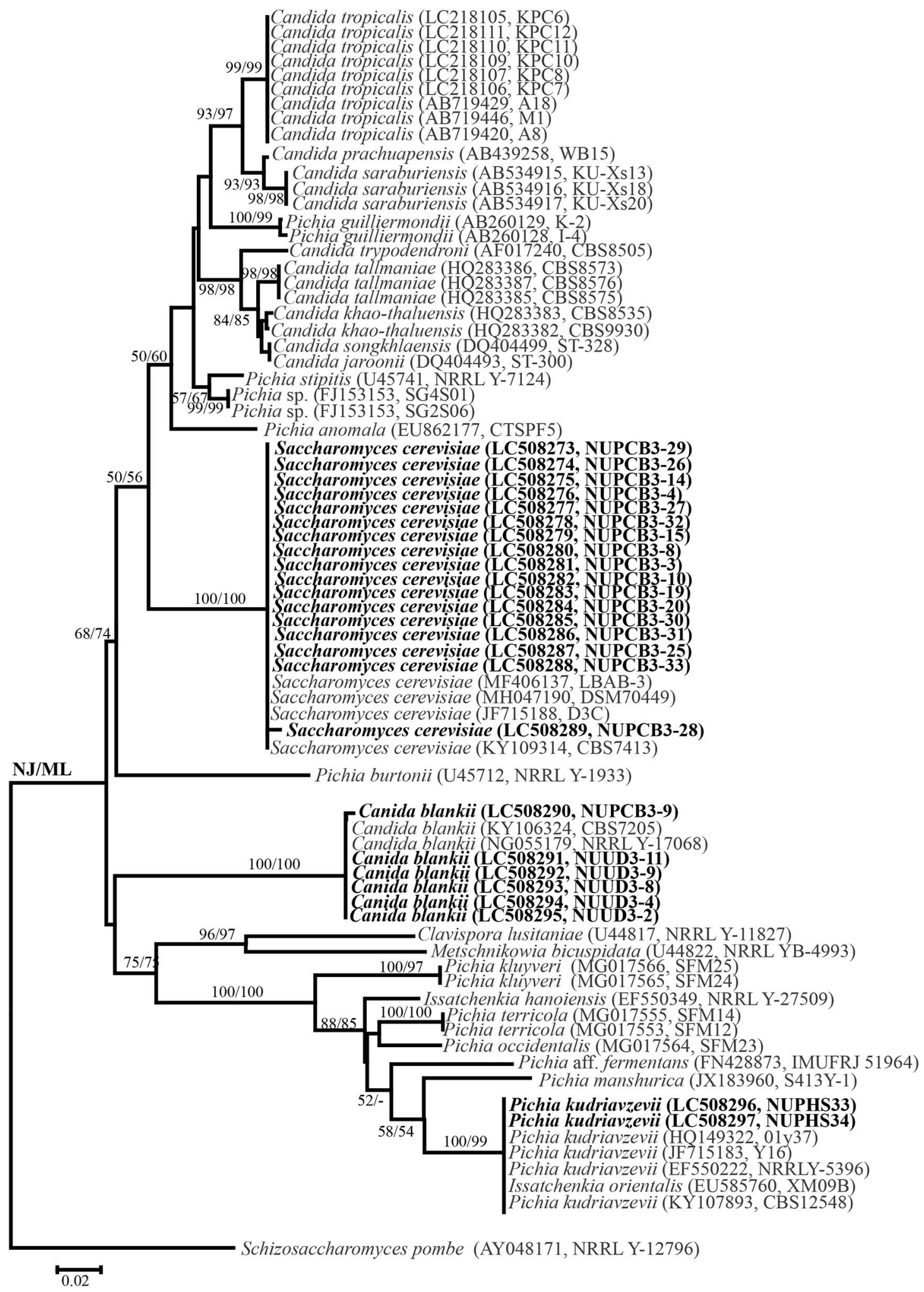

Fig. 4 The maximum likelihood phylogenetic tree showing the relationship between Thai thermolerant yeast and related taxa. Bootstrap supports greater than 50\% are indicated at branch node. The studied Thai strains are in black and bold letters. Schizosaccharomyces pombe NRRL Y-12796 was used as the outgroup species. 
an enrichment technique using 4\% (v/v) ethanol. Overall, extensive screening and identification of microorganisms from distinct ecological niches such as tropical and subtropical regions and other natural habitats has been carried out. Moreover, improving our understanding of the biochemical and molecular mechanisms of the ethanol tolerance in yeast and how cells respond to ethanol stress can promote the development of strategies for enhancing microbial ethanol tolerance.

Previously, Chaudhary and Karita noted that the anaerobic release of $\mathrm{CO}_{2}$ into Durham tubes is not very precise for recognizing slowly fermenting yeast species [26]. Nevertheless, fermentation tubes have been used for the first screening for ethanol production by several investigators $[7,15,17]$. In this study, the ethanol production efficiency of 2 P. kudriavzevii isolates, NUPHS33 and NUPHS34, were evaluated at high temperatures using glucose as the carbon source, and the results demonstrated that the maximum ethanol concentrations were significantly different, depending on the yeast strain and fermentation temperature (Table 2). In this study, the ethanol concentration of NUPHS33 at a temperature of $40^{\circ} \mathrm{C}$ was lower than that at temperatures of 37 and $45^{\circ} \mathrm{C}$, which is similar to S. cerevisiae C3723, Candida tropicalis CTB18 and C. tropicalis KK19 $[2,5]$. For example, Auesukaree et al [2] described the isolation of $S$. cerevisiae C3723 which produced ethanol at 32.5, 31.2 and $38.6 \mathrm{~g} / 1$ at temperatures of 30,37 and $41{ }^{\circ} \mathrm{C}$, respectively. Chamnipa et al [5] isolated C. tropicalis CTB18 capable of producing ethanol with concentrations of 51.54, 35.94 and $51.54 \mathrm{~g} / \mathrm{l}$; similarly, C. tropicalis KK19 produced ethanol at 53.93, 35.49 and $52.37 \mathrm{~g} / 1$ at 37,40 and $45^{\circ} \mathrm{C}$, respectively. So far, therefore, the knowledge involved in cellular functions may have also been correlated with high temperature ethanol production. Further studies are needed to gain a better understanding of the cellular function and molecular mechanisms conferring yeast thermotolerance as applied to ethanol production. A comparative analysis of the ethanol production by our newly isolated P. kudriavzevii, NUPHS33 and NUPHS34, and other isolates of $P$. kudriavzevii as reported in the previous literature is shown in Table 3. The differences in ethanol production efficiency are potentially attributable to differences in yeast isolates or the raw substrate used for fermentation. Two other factors may also have an influence. The first is "cross-tolerance" in which one type of stress enhances protection against other stressors, while the second is the effect of glucose on protecting cell membranes from temperature stress. The effects of carbohydrates and a disaccharide, trehalose, have been well documented in the protection of cells against stress; however, the protective effects of glucose have not yet been defined [27]. Thus, further investigations are required to resolve the phenomenon of acquiring temperature tolerance with high glucose concentrations as the carbon source.

Among the yeast species known and used in the fermentation process, several thermotolerant yeasts such as S. cerevisiae, K. marxianus, Pichia sp. and Candida sp. have been characterized as robust industrial strains for ethanol production $[2,7,14$, 27]. Several studies have shown the extremely robust physiology of $P$. kudriavzevii in applications for the bioethanol industry $[6,28,29]$. However, there are only a limited number of reports on the successful selection and isolation of yeasts capable of growth or fermentation at or above $40^{\circ} \mathrm{C}$. As the temperature increases during the fermentation process, ethanol productivity strongly declines because of the greater ethanol interference. Based on the results of the current study, it has been shown that the newly isolated P. kudriavzevii NUPHS33 and P. kudriavzevii NUPHS34 strains are suitable thermotolerant yeasts for high-temperature ethanol fermentation in the biotechnological industry. The ethanol production from glucose by $P$. kudriavzevii NUPHS33 and $P$. kudriavzevii NUPHS34 was higher than that in previous studies, indicating that these yeasts are good candidates to produce ethanol on a large scale. Although P. kudriavzevii demonstrated advantages in ethanol fermentation and a high tolerance to ethanol stress, inhibitors derived from the biomass deconstruction processes have harmful effects on microorganisms. The effects of lignocellulose biomass-derived inhibitors such as phenolic acids, inorganic salts and furan aldehydes on the fermenting microorganisms have become a challenge to the improvement of industrial biofuel production. Strategies including mutagenesis as well as genetic and metabolic engineering have been applied to construct robust strains for bioethanol production from lignocellulose feedstock [30-32]. Beyond this, further study into the molecular mechanisms under the various stress factors during the fermentation process such as the heat shock response, oxidative stress defense and glycolytic metabolism should be undertaken. 
Table 3 Comparison of ethanol tolerance and ethanol production at a temperature of $45^{\circ} \mathrm{C}$ by $P$. kudriavzevii NUPHS33 and NUPHS34 and other P. kudriavzevii isolates.

\begin{tabular}{|c|c|c|c|c|c|c|}
\hline Isolate & $\begin{array}{l}\text { Source of } \\
\text { sample }\end{array}$ & $\begin{array}{l}\text { Level of ethanol } \\
\text { tolerance }(\% \mathrm{v} / \mathrm{v})\end{array}$ & $\begin{array}{l}\text { Initial carbon source } \\
(\% \mathrm{w} / \mathrm{v})\end{array}$ & $\begin{array}{c}\text { Ethanol } \\
\text { concentration }(\mathrm{g} / \mathrm{l})\end{array}$ & $\begin{array}{l}\text { Ethanol yield } \\
\text { (YP/S; g/g) }\end{array}$ & Reference \\
\hline S1-2 & Soil & 10 & $16 \%(\mathrm{w} / \mathrm{v})$ glucose & 36.12 & 0.23 & [6] \\
\hline S10-2 & Soil & 10 & $16 \%(w / v)$ glucose & 37.09 & 0.23 & [6] \\
\hline CPY514-1 & Soil & no report & $\begin{array}{l}\text { Cassava starch hydrolysate } \\
18 \%(\mathrm{w} / \mathrm{v}) \text { reducing sugar }\end{array}$ & 23.59 & 0.13 & {$[7]$} \\
\hline PBB511-1 & Soil & no report & $\begin{array}{l}\text { Cassava starch hydrolysate } \\
18 \%(\mathrm{w} / \mathrm{v}) \text { reducing sugar }\end{array}$ & 26.22 & 0.15 & {$[7]$} \\
\hline TM512-2 & Soil & no report & $\begin{array}{l}\text { Cassava starch hydrolysate } \\
18 \%(\mathrm{w} / \mathrm{v}) \text { reducing sugar }\end{array}$ & 26.2 & 0.15 & [7] \\
\hline TG514-2 & Soil & no report & $\begin{array}{l}\text { Cassava starch hydrolysate } \\
18 \%(\mathrm{w} / \mathrm{v}) \text { reducing sugar }\end{array}$ & 22.51 & 0.13 & [7] \\
\hline RZ8-1 & Plant orchard & 12 & $16 \%(\mathrm{w} / \mathrm{v})$ glucose & 35.14 & 0.22 & {$[4]$} \\
\hline NUNS-4 & Soil & 13 & $16 \%(\mathrm{w} / \mathrm{v})$ glucose & 54.30 & 0.34 & {$[27]$} \\
\hline NUNS-5 & Soil & 13 & $16 \%(w / v)$ glucose & 37.73 & 0.24 & [27] \\
\hline NUNS-6 & Soil & 13 & $16 \%(\mathrm{w} / \mathrm{v})$ glucose & 42.28 & 0.26 & [27] \\
\hline NUPHS33 & Soil & 15 & $16 \%(\mathrm{w} / \mathrm{v})$ glucose & 61.51 & 0.38 & This study \\
\hline NUPHS34 & Soil & 15 & $16 \%(\mathrm{w} / \mathrm{v})$ glucose & 58.95 & 0.37 & This study \\
\hline
\end{tabular}

\section{CONCLUSION}

An extensive screening for thermotolerant yeasts with ethanol tolerance to use in high-temperature ethanol fermentation was performed in the present study. The ability of the P. kudriavzevii yeasts NUPHS33 and NUPHS34 for elevated temperature ethanol production and their tolerance to ethanol stress was significantly greater than that of the reference strain used. The 2 isolates of $P$ kudriavzevii NUPHS33 and NUPHS34 not only exhibited growth at a temperature of $45^{\circ} \mathrm{C}$, but also were tolerant to the stress of ethanol at $15 \%(\mathrm{v} / \mathrm{v})$. Thus, these strains are potential candidates for industrial applications in the ethanol fermentation industry.

\section{Appendix A. Supplementary data}

Supplementary data associated with this article can be found at http://dx.doi.org/10.2306/ scienceasia1513-1874.2021.009.

Acknowledgements: This research was funded by the National Research Council of Thailand, grant number 2562NRCT32012 (R2562A099, Naresuan University). The authors are grateful to Professor Dr. Duncan R. Smith (Institute of Molecular Biosciences, Mahidol University, Thailand) for English editing and scientific proofreading of this manuscript. The authors declare no conflict of interest.

\section{REFERENCES}

1. Tolieng V, Kunthiphun S, Savarajara A, Tanasupawat $S$ (2018) Diversity of yeasts and their ethanol production at high temperature. J Appl Pharm Sci 8, 136-142.

2. Auesukaree C, Koedrith P, Saenpayavai P, Asvarak T, Benjaphokee S, Sugiyama M, Kaneko M, Harashima
S, et al (2012) Characterization and gene expression profiles of thermotolerant Saccharomyces cerevisiae isolates from Thai fruits. $J$ Biosci Bioeng 114, 144-149.

3. Lin Y, Tanaka S (2006) Ethanol fermentation from biomass resources: current state and prospects. Appl Microbiol Biotechnol 6, 627-642.

4. Phomikhet P, Lorliam W, Thaniyavarn S, Tanasupawat S, Savarajara A (2019) Supplementation of sugarcane molasses for maximization of ethanol production by Saccharomyces cerevisiae using response surface method. ScienceAsia 45, 229-235.

5. Chamnipa N, Thanonkeo S, Klanrit P, Thanonkeo $P$ (2018) The potential of the newly isolated thermotolerant yeast Pichia kudriavzevii RZ8-1 for hightemperature ethanol production. Braz J Microbiol 49, 378-391.

6. Koutinas M, Patsalou M, Stavrinou S, Vyrides I (2016) High temperature alcoholic fermentation of orange peel by the newly isolated thermotolerant Pichia kudriavzevii KVMP10. Lett Appl Microbiol 62, 75-83.

7. Buddiwong S, Thanonkeo S, Phetsom J, Jaisil P, Thanonkeo P (2014) Screening of thermotolerant yeast isolated from sugarcane plantations in Northeastern part of Thailand. KKU Res J 19, 217-223.

8. Kaewkrajay C, Dethoup T, Limtong S (2014) Ethanol production from cassava using a newly isolated thermotolerant yeast strain. ScienceAsia 40, 268-277.

9. Limtong S, Yongmanitchai W, Kawasaki H, Fujiyama K (2009) Wickerhamomyces edaphicus sp. nov. and Pichia jaroonii sp. nov., two ascomycetous yeast species isolated from forest soil in Thailand. FEMS Yeast Res 9, 504-510.

10. Techaparin A, Thanonkeo P, Klanrit P (2017) Hightemperature ethanol production using thermotolerant yeast newly isolated from Greater Mekong Subregion. Braz J Microbiol 48, 461-475. 
11. Hesham Ael L, Mohamed H (2011) Molecular genetic identification of yeast strains isolated from Egyptian soils for solubilization of inorganic phosphates and growth promotion of corn plants. J Microbiol Biotechnol 21, 55-61.

12. Sree NK, Sridhar M, Suresh K, Banat IM, Rao LV (2000) Isolation of thermotolerant, osmotolerant, flocculating Saccharomyces cerevisiae for ethanol production. Bioresour Technol 72, 43-46.

13. Nitiyon S, Keo-Oudone C, Murata M, Lertwattanasakul N, Limtong S, Kosaka T, Yamada M (2016) Efficient conversion of xylose to ethanol by stress-tolerant Kluyveromyces marxianus BUNL-21. Springerplus 5, 1-12.

14. Limtong S, Sringiew C, Yongmanitchai W (2007) Production of fuel ethanol at high temperature from sugar cane juice by a newly isolated Kluyveromyces marxianus. Bioresour Technol 98, 3367-3674.

15. Pongcharoen P, Kawano-Kawada M (2018) Identification and characterization of Candida tropicalis isolated from soil of sugarcane plantation in Thailand for ethanol production. Asia Pac J Sci Technol 23, APST-23-03-01.

16. Phoung DNT, Thanonkeo P, Phong HX (2012) Screening useful isolated yeasts for ethanol fermentation at high temperature. Int J Appl Sci Technol 2, 65-71.

17. Yuangsaard N, Yongmanitchai W, Yamada M, Limtong S (2013) Selection and characterization of a newly isolated thermotolerant Pichia kudriavzevii strain for ethanol production at high temperature from cassava starch hydrolysate. Antonie van Leeuwenhoek 103, 577-588.

18. Looke M, Kristjuhan K, Kristjuhan A (2011) Extraction of genomic DNA from yeasts for PCR-based applications. BioTechniques 50, 325-328.

19. Kurtzman CP, Robnett CJ (1998) Identification and phylogeny of ascomycetous yeasts from analysis of nuclear large subunit (26S) ribosomal DNA partial sequences. Antonie van Leeuwenhoek 73, 331-371.

20. Thompson JD, Higgins DG, Gibson TJ (1994) CLUSTAL W: Improving the sensitivity of progressive multiple sequence alignment through sequence weighting, position-specific gap penalties and weight matrix choice. Nucleic Acids Res 22, 4673-4680.

21. Guindon S, Dufayard JF, Lefort V, Anisimova M, Hordijk W, Gascuel O (2010) New algorithms and methods to estimate maximum-likelihood phylogenies: assessing the performance of PhyML 3.0. Syst
Biol 59, 307-321.

22. Kumar S, Stecher G, Tamura K (2016) MEGA7: Molecular evolutionary genetics analysis version 7.0 for bigger datasets. Mol Biol Evol 33, 1870-1874.

23. Alexandre H, Ansanay-Galeote V, Dequin S, Blondin B (2001) Global gene expression during short-term ethanol stress in Saccharomyces cerevisiae. FEBS Lett 498, 98-103.

24. Birch RM, Walker GM (2000) Influence of magnesium ions on heat shock and ethanol stress responses of Saccharomyces cerevisiae. Enzyme Microb Technol 26, 678-687.

25. Joshi BH, Patel DK (2017) Screening and characterization of newly isolated thermotolerant and ethanogenic strain of Pichia kudriavzevii. Int J Agric Environ Biotechnol 10, 115-123.

26. Chaudhary A, Karita S (2017) Screening of yeast isolates from flowers for effective ethanol production. Turk J Biol 41, 890-900.

27. Costa DA, de Souza CJ, Costa PS, Rodrigues MQ, dos Santos AF, Lopes MR, Genier HLA, Silveira WB, et al (2014) Physiological characterization of thermotolerant yeast for cellulosic ethanol production. Appl Microbiol Biotechnol 98, 3829-3840.

28. Pongcharoen P, Chawneua J, Tawong W (2018) High temperature alcoholic fermentation by new thermotolerant yeast strains Pichia kudriavzevii isolated from sugarcane field soil. Agr Nat Resour 52, 511-518.

29. Yuan SF, Guo GL, Hwang WS (2017) Ethanol production from dilute-acid steam exploded lignocellulosic feedstocks using an isolated multistress-tolerant Pichia kudriavzevii strain. Microb Biotechnol 10, 1581-1590.

30. Jönsson L, Martín C (2016) Pretreatment of lignocellulose: Formation of inhibitory by-products and strategies for minimizing their effects. Bioresour Technol 199, 103-112.

31. Gu H, Zhu Y, Peng Y, Liang X, Liu X, Shao L, $\mathrm{Xu} \mathrm{Y,} \mathrm{Xu} \mathrm{Z,} \mathrm{et} \mathrm{al} \mathrm{(2019)} \mathrm{Physiological} \mathrm{mecha-}$ nism of improved tolerance of Saccharomyces cerevisiae to lignin-derived phenolic acids in lignocellulosic ethanol fermentation by short-term adaptation. Biotechnol Biofuels 12, 1-14.

32. Yang Y, Hu M, Tang Y, Gene B, Qiu M, He Q, Chen S, Wang X, et al (2018) Progress and perspective on lignocellulosic hydrolysate inhibitor tolerance improvement in Zymomonas mobilis. Bioresour Bioprocess 5, $1-12$. 


\section{Appendix A. Supplementary data}

Table S1 Locations of sample collection. Twenty-four soil sampling sites from 8 provinces were collected. Each province consisted of 3 sampling sites from different locations indicated as 1, 2 and 3. Abbreviations: Tak, TK; Sukhothai, ST; Uttaradit, UD; Phitsanulok, PHS; Kamphaeng Phet, KP; Phichit, PC; Phetchabun, PCB and Nakhon Sawan, NS.

\begin{tabular}{|c|c|}
\hline Province & Location \\
\hline Tak (TK) & $\begin{array}{l}116^{\circ} 55^{\prime} 01.4^{\prime \prime} \mathrm{N} 98^{\circ} 34^{\prime} 09.3^{\prime \prime} \mathrm{E} \\
216^{\circ} 28^{\prime} 12.0^{\prime \prime} \mathrm{N} 98^{\circ} 41^{\prime} 56.0^{\prime \prime} \mathrm{E} \\
316^{\circ} 45^{\prime} 00.9^{\prime \prime} \mathrm{N} 98^{\circ} 34^{\prime} 54.4^{\prime \prime} \mathrm{E}\end{array}$ \\
\hline Sukhothai(ST) & $\begin{array}{l}117^{\circ} 09^{\prime} 56.4^{\prime \prime} \mathrm{N} 99^{\circ} 52^{\prime} 05.0^{\prime \prime} \mathrm{E} \\
217^{\circ} 15^{\prime} 22.3^{\prime \prime} \mathrm{N} 99^{\circ} 57^{\prime} 24.8^{\prime \prime} \mathrm{E} \\
317^{\circ} 18^{\prime} 39.6^{\prime \prime} \mathrm{N} 99^{\circ} 57^{\prime} 16.9^{\prime \prime} \mathrm{E}\end{array}$ \\
\hline Uttaradit (UD) & $\begin{array}{l}117^{\circ} 13^{\prime} 55.1^{\prime \prime} \mathrm{N} 100^{\circ} 03^{\prime} 05.0^{\prime \prime} \mathrm{E} \\
217^{\circ} 27^{\prime} 40.8^{\prime \prime} \mathrm{N} 100^{\circ} 17^{\prime} 44.1^{\prime \prime} \mathrm{E} \\
317^{\circ} 27^{\prime} 28.4^{\prime \prime} \mathrm{N} 100^{\circ} 10^{\prime} 52.5^{\prime \prime} \mathrm{E}\end{array}$ \\
\hline Phitsanulok (PHS) & $\begin{array}{l}116^{\circ} 59^{\prime} 02.2^{\prime \prime} \mathrm{N} 100^{\circ} 12^{\prime} 46.9^{\prime \prime} \mathrm{E} \\
216^{\circ} 42^{\prime} 51.1^{\prime \prime} \mathrm{N} 100^{\circ} 06^{\prime} 15.3^{\prime \prime} \mathrm{E} \\
316^{\circ} 42^{\prime} 54.0^{\prime \prime} \mathrm{N} 100^{\circ} 15^{\prime} 10.1^{\prime \prime} \mathrm{E}\end{array}$ \\
\hline Kamphaeng Phet (KP) & $\begin{array}{ll}1 & 16^{\circ} 29^{\prime} 40.5^{\prime \prime} \mathrm{N} 99^{\circ} 38^{\prime} 34.1^{\prime \prime} \mathrm{E} \\
2 & 16^{\circ} 28^{\prime} 56.5^{\prime \prime} \mathrm{N} 99^{\circ} 48^{\prime} 56.6^{\prime \prime} \mathrm{E} \\
3 & 16^{\circ} 21^{\prime} 02.5^{\prime \prime} \mathrm{N} 99^{\circ} 52^{\prime} 06.2^{\prime \prime} \mathrm{E}\end{array}$ \\
\hline Phichit (PC) & $\begin{array}{ll}1 & 16^{\circ} 14^{\prime} 43.4^{\prime \prime} \mathrm{N} 100^{\circ} 07^{\prime} 30.3^{\prime \prime} \mathrm{E} \\
2 & 16^{\circ} 21^{\prime} 26.3^{\prime \prime} \mathrm{N} 100^{\circ} 04^{\prime} 21.8^{\prime \prime} \mathrm{E} \\
3 & 16^{\circ} 16^{\prime} 00.7^{\prime \prime} \mathrm{N} 100^{\circ} 11^{\prime} 21.3^{\prime \prime} \mathrm{E}\end{array}$ \\
\hline Phetchabun (PCB) & $\begin{array}{l}115^{\circ} 33^{\prime} 46.1^{\prime \prime} \mathrm{N} 101^{\circ} 03^{\prime} 30.4^{\prime \prime} \mathrm{E} \\
215^{\circ} 25^{\prime} 14.1^{\prime \prime} \mathrm{N} 101^{\circ} 04^{\prime} 33.9^{\prime \prime} \mathrm{E} \\
315^{\circ} 50^{\prime} 23.5^{\prime \prime} \mathrm{N} 100^{\circ} 58^{\prime} 36.1^{\prime \prime} \mathrm{E}\end{array}$ \\
\hline Nakhon Sawan (NS) & $\begin{array}{l}115^{\circ} 16^{\prime} 22.3^{\prime \prime} \mathrm{N} 100^{\circ} 22^{\prime} 20.3^{\prime \prime} \mathrm{E} \\
215^{\circ} 29^{\prime} 55.9^{\prime \prime} \mathrm{N} 100^{\circ} 14^{\prime} 43.8^{\prime \prime} \mathrm{E} \\
31^{\circ} 55^{\prime} 47.2^{\prime \prime} \mathrm{N} 99^{\circ} 59^{\prime} 58.4^{\prime \prime} \mathrm{E}\end{array}$ \\
\hline
\end{tabular}


Table S2 $\mathrm{CO}_{2}$ production of 25 yeast isolates and $S$. cerevisiae TISTR5606 using a Durham fermentation tube. A sugar fermentation testing using $2 \%(\mathrm{w} / \mathrm{v})$ glucose, fructose, sucrose or xylose as a carbon source.

\begin{tabular}{|c|c|c|c|c|c|c|}
\hline \multirow{3}{*}{ No. } & \multirow{3}{*}{ Group } & \multirow{3}{*}{ Isolate } & \multicolumn{4}{|c|}{ Percentage of gas production at temperature of } \\
\hline & & & \multirow{2}{*}{$\frac{45^{\circ} \mathrm{C}}{\text { Glucose }}$} & \multicolumn{3}{|c|}{$30^{\circ} \mathrm{C}$} \\
\hline & & & & Fructose & Sucrose & Xylose \\
\hline 1 & NUPCB & PCB3-3 & 43 & 12 & 14 & 8 \\
\hline 2 & & PCB3-4 & 48 & 12 & 12 & 6 \\
\hline 3 & & PCB3-8 & 37 & 12 & 14 & 6 \\
\hline 4 & & PCB3-9 & 47 & 14 & 12 & 8 \\
\hline 5 & & PCB3-10 & 36 & 10 & 12 & 8 \\
\hline 6 & & PCB3-14 & 38 & 10 & 12 & 8 \\
\hline 7 & & PCB3-15 & 32 & 12 & 12 & 8 \\
\hline 8 & & PCB3-19 & 33 & 8 & 10 & 8 \\
\hline 9 & & PCB3-20 & 35 & 10 & 14 & 8 \\
\hline 10 & & PCB3-25 & 33 & 12 & 12 & 8 \\
\hline 11 & & PCB3-26 & 30 & 12 & 12 & 8 \\
\hline 12 & & РCB3-27 & 35 & 12 & 12 & 8 \\
\hline 13 & & PCB3-28 & 32 & 14 & 10 & 8 \\
\hline 14 & & PCB3-29 & 38 & 14 & 12 & 8 \\
\hline 15 & & PCB3-30 & 32 & 8 & 14 & 6 \\
\hline 16 & & PCB3-31 & 37 & 10 & 10 & 8 \\
\hline 17 & & PCB3-32 & 52 & 10 & 12 & 8 \\
\hline 18 & & PCB3-33 & 33 & 10 & 8 & 10 \\
\hline 19 & NUUD3 & UD3-2 & 45 & 0 & 0 & 0 \\
\hline 20 & & UD3-4 & 38 & 0 & 0 & 0 \\
\hline 21 & & UD3-8 & 35 & 0 & 0 & 0 \\
\hline 22 & & UD3-9 & 32 & 0 & 0 & 0 \\
\hline 23 & & UD3-11 & 45 & 0 & 0 & 0 \\
\hline 24 & NUPHS & PHS33 & 65 & 0 & 0 & 0 \\
\hline 25 & & PHS34 & 94 & 0 & 0 & 0 \\
\hline 26 & S. cerevisiae & TISTR5606 & 0 & 0 & 76 & 0 \\
\hline
\end{tabular}


Table S3 Ethanol production of selected thermotolerant yeast isolates at a temperature of $45^{\circ} \mathrm{C}$ for $48 \mathrm{~h}$ incubation time compared to that of the reference isolate $S$. cerevisiae TISTR5606. Data were expressed as mean \pm standard deviation. ND means not detectable.

\begin{tabular}{lc}
\hline Isolate & Ethanol concentration $(\mathrm{g} / \mathrm{l})$ \\
\hline NUPCB3-3 & ND \\
NUPCB3-4 & ND \\
NUPCB3-8 & $0.47 \pm 0.01$ \\
NUPCB3-9 & $0.56 \pm 0.02$ \\
NUPCB3-10 & $0.63 \pm 0.05$ \\
NUPCB3-14 & ND \\
NUPCB3-15 & ND \\
NUPCB3-19 & $0.31 \pm 0.03$ \\
NUPCB3-20 & ND \\
NUPCB3-25 & ND \\
NUPCB3-26 & $0.77 \pm 0.02$ \\
NUPCB3-27 & ND \\
NUPCB3-28 & ND \\
NUPCB3-29 & ND \\
NUPCB3-30 & ND \\
NUPCB3-31 & ND \\
NUPCB3-32 & ND \\
NUPCB3-33 & ND \\
NUUD3-2 & $8.89 \pm 0.42$ \\
NUUD3-4 & $8.93 \pm 0.04$ \\
NUUD3-8 & $3.61 \pm 0.28$ \\
NUUD3-9 & $6.38 \pm 0.27$ \\
NUUD3-11 & $6.27 \pm 0.22$ \\
\hline
\end{tabular}




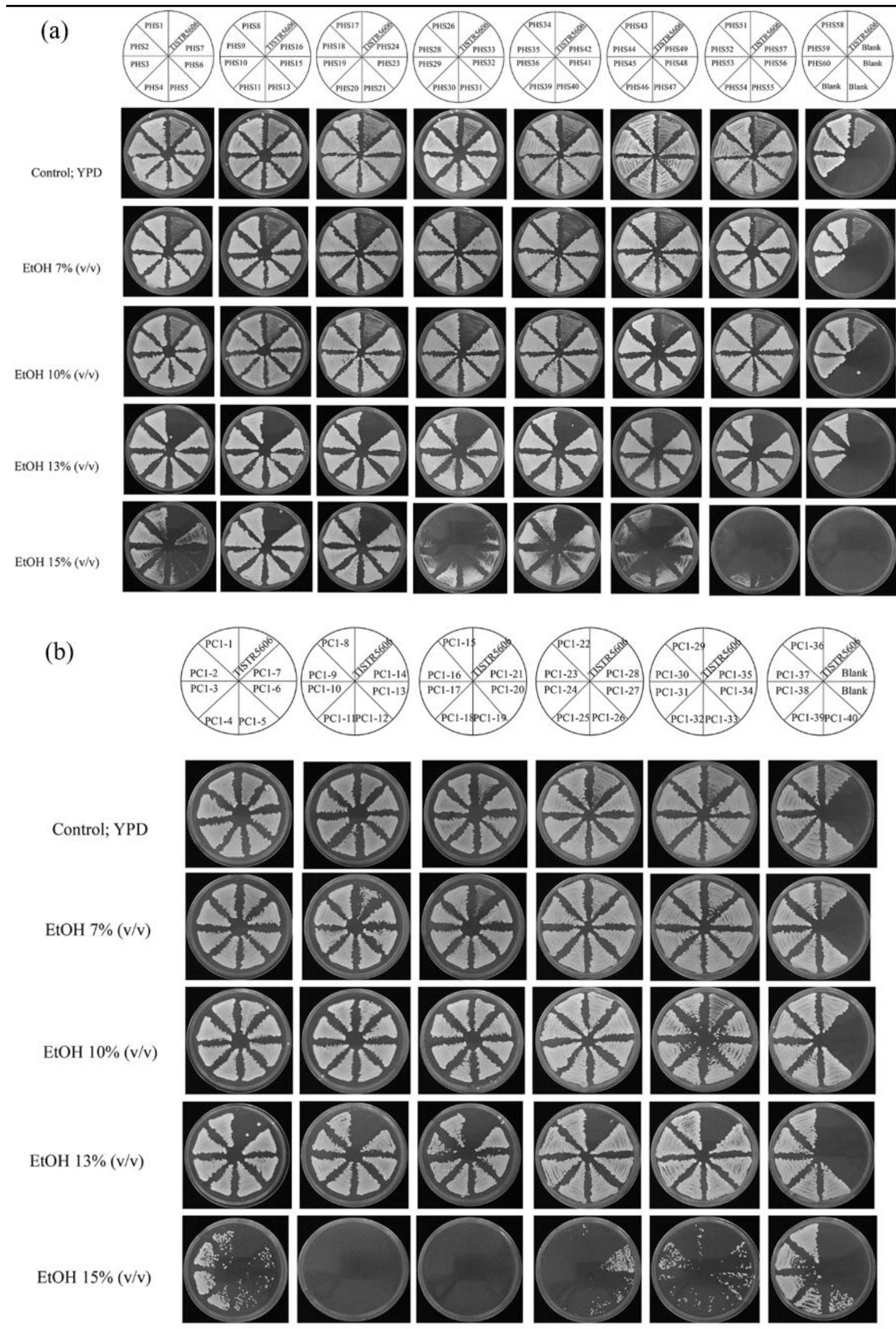



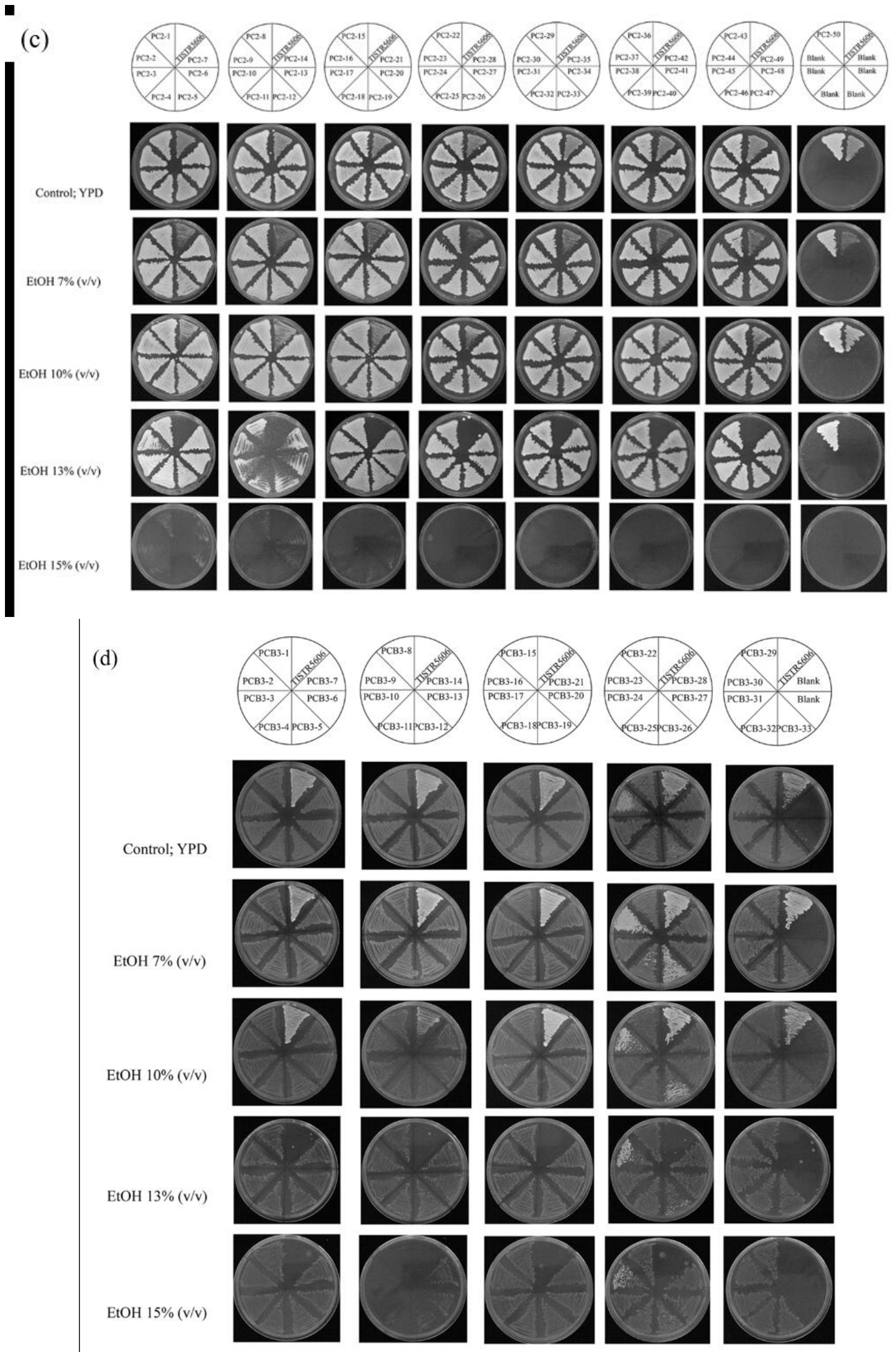
(e)
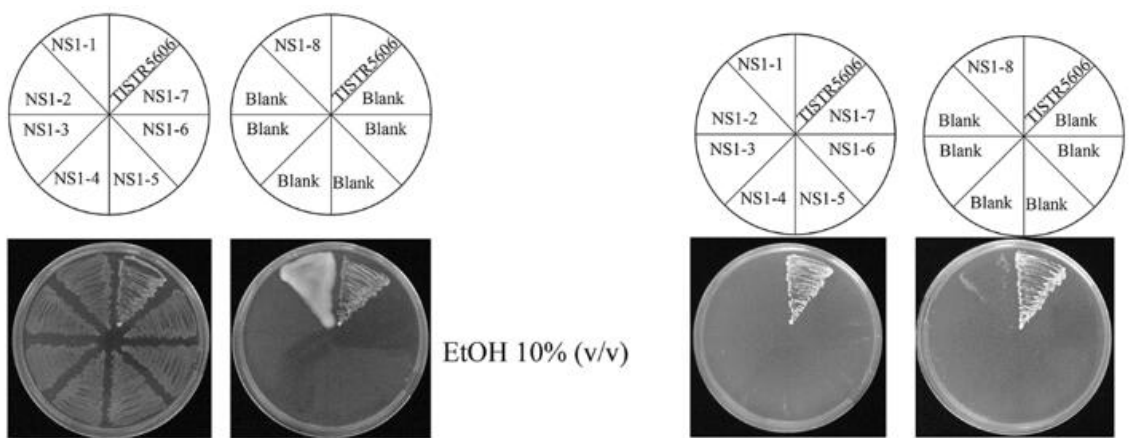

EtOH $7 \%(v / v)$
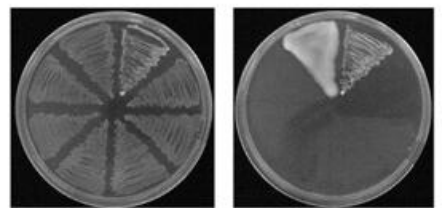

EtOH $10 \%(v / v)$
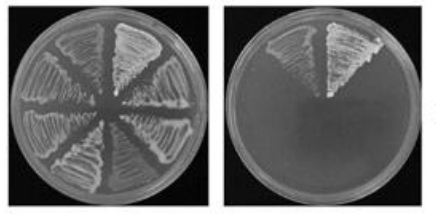

$\mathrm{EtOH} 13 \%(\mathrm{v} / \mathrm{v})$
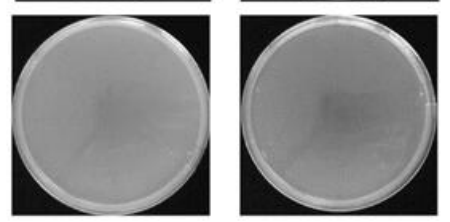

(f)
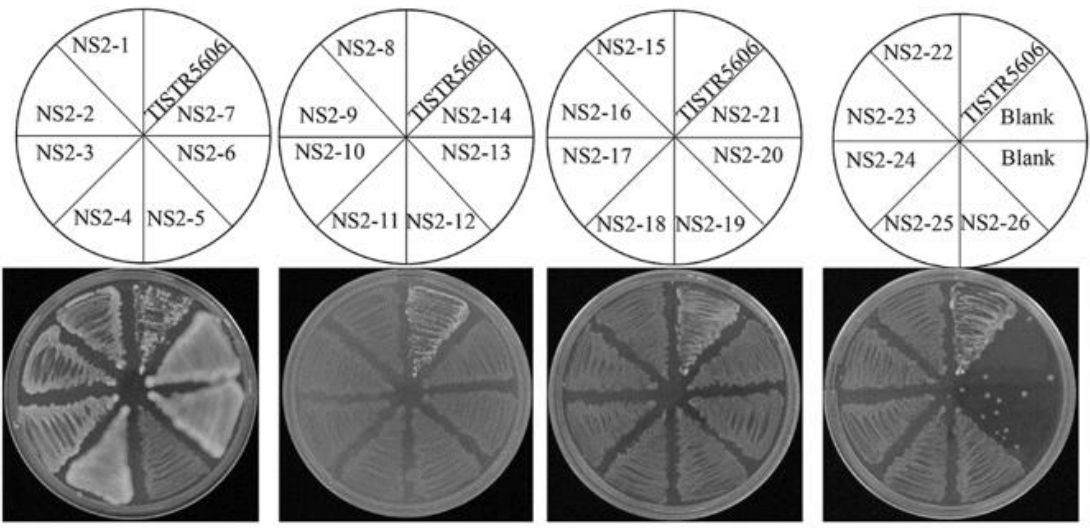

EtOH 7\% (v/v)
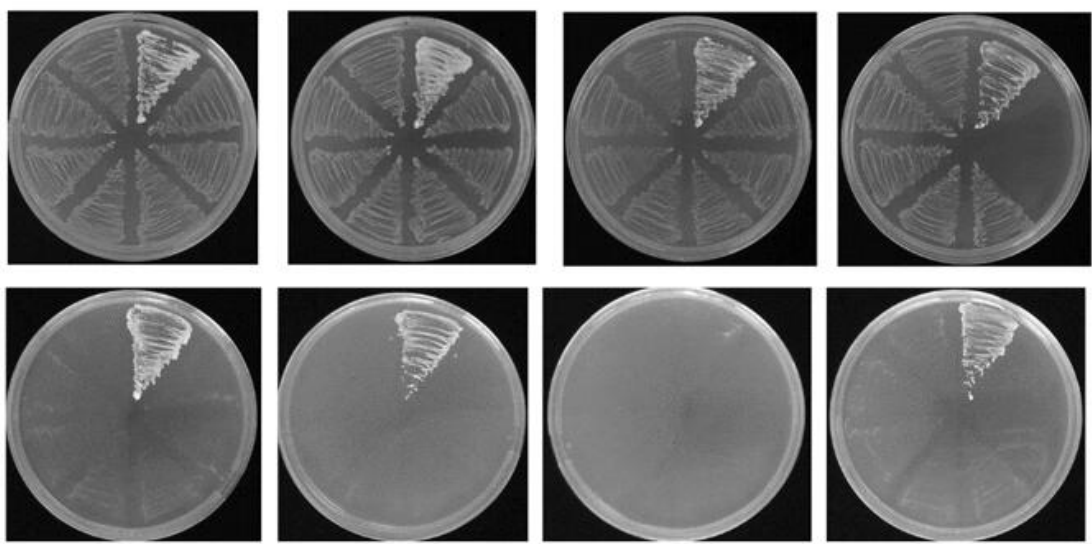

EtOH $10 \%(v / v)$
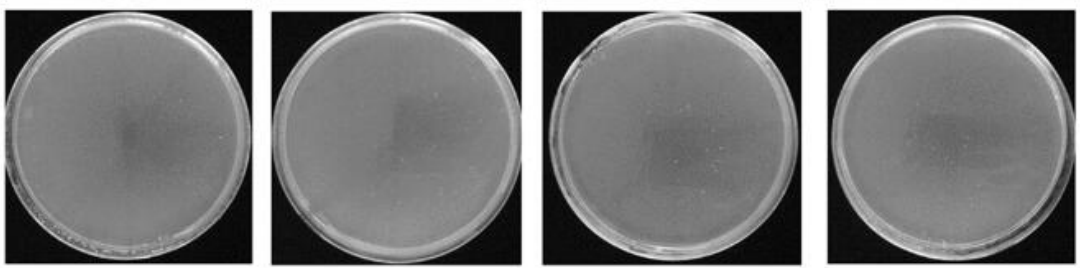

Fig. S2 Effect of ethanol stress on the cell growth of selected thermotolerant yeasts and S. cerevisiae TISTR5606 on YPD agar plates after incubation at temperature of $30^{\circ} \mathrm{C}$. Each sample was isolates of (a) PHS1 to PHS60; (b) PC1-1 to PC1-40; (c) PC2-1 to PC2-50; (d) PCB3-1 to PCB3-33; (e) NS1-1 to NS1-8 and (f) NS2-1 to NS2-26. 